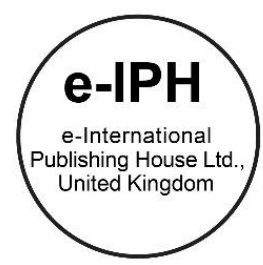

Live Beyond Buildings:

\title{
The street as the everyday living space in Istanbul, Turkey
}

\author{
Anak Warakanyaka, Paramita Atmodiwirjo \\ Universitas Indonesia, Kampus UI, Depok 16424, Indonesia \\ ayuwarakanyaka@ui.ac.id \\ Tel: +6281280793307
}

\begin{abstract}
This paper attempts to reveal the importance of the everyday temporal living space on the street as the agency to improve the quality of life in the city. The temporal living space is the collective public space that is produced by the local inhabitants as the response to fulfil their sociocultural needs. This study employed time-based behavioural and spatial mappings to reveal how spatial alteration was employed by the locals, producing the particular spatial programming and atmospheres that allowed the interiorization of the street. The mappings would also reveal how the interaction of the local inhabitants within this temporal living space had impacts on the general wellbeing and the spatial identity of the city. The findings of this study were translated into an interior architectural design exercise, by developing design methods that were adopted from the locals' spatial mechanisms in producing their temporal outdoor living spaces.
\end{abstract}

Keywords: Interior; Temporal Living Space; Design Method; Quality of Life

eISSN: 2398-4287@ 2017. The Authors. Published for AMER ABRA by e-International Publishing House, Ltd., UK. This is an open access article under the CC BYNCND license (http://creativecommons.org/licenses/by-nc-nd/4.0/). Peer-review under responsibility of AMER (Association of Malaysian Environment-Behaviour Researchers), ABRA (Association of Behavioural Researchers on Asians) and cE-Bs (Centre for Environment-Behaviour Studies), Faculty of Architecture, Planning \& Surveying, Universiti Teknologi MARA, Malaysia.

https://doi.org/10.21834/e-bpj.v2i6.995

\subsection{Introduction}

There is a shift in attitude toward the living space, from strong attachment to the existence of houses or the physical attributes it embodied, to understanding it as the setting where particular sets of emotions could be felt. The living space, as well as the domestic space, is encompassed by the feeling of ownership, of refugee, and of affection (Rybczynksi, 2011). Such nature of living space makes it become a boundless entity which is not restricted to any physical forms, and rather it becomes a psychological setting that is constantly made and remade by its inhabitants to experience these emotions. The existence of living space is expanded from the private interior to the public space. Its presence could also be found in the least expectable domain, in the transitory and supporting system of the city, the street.

The utilisation of the street as the living space is a common spatial practice in developing countries. This living space is usually temporal and unauthorised, yet it is explicitly functional. It is produced by traditional activities and culture support where people gather as equal and the socio-political aspect of the city (Amoroso, 2014). Despite the fact that it has an important role in ensuring the physical and emotional well-being of the locals, this spatial practice is often marginalised as it usually does not comply with the idea of the ideal city and highly associated with the marginal communities (Shaw and Hudson, 2014 and Yatmo, 2008).

This paper aims to reveal the importance of the temporal living space emerged on the street to investigate the role of the informal and ephemeral space in improving the quality of life in the city. This paper would employ behaviour mapping in its relation with time, which would reveal the spatial mechanism of this temporal space that alters the atmospheres, social activities and spatial

eISSN: 2398-4287@ 2017. The Authors. Published for AMER ABRA by e-International Publishing House, Ltd., UK. This is an open access article under the CC BYNCND license (http://creativecommons.org/licenses/by-nc-nd/4.0/). Peer-review under responsibility of AMER (Association of Malaysian Environment-Behaviour Researchers), ABRA (Association of Behavioural Researchers on Asians) and cE-Bs (Centre for Environment-Behaviour Studies), Faculty of Architecture, Planning \& Surveying, Universiti Teknologi MARA, Malaysia.

https://doi.org/10.21834/e-bpj.v2i6.995 
programming of the street to meet the sociocultural needs of its inhabitant. This study not only looks into spatial elements that shaped the environment but also investigates the people behaviour in space to see how they contribute to shaping this temporal space. The result of the mapping would suggest possible spatial strategies which are suitable for enhancing the interaction between urban actors and their temporal living space to improve their wellbeing personally and collectively.

The findings of this study were then translated into an interior architectural design exercise which was done as part of the IMIAD Exchange Programme 2015 in Istanbul Turkey. The exercise employed design strategies based on the behavioural and spatial mapping on how people utilise the street as living space in Faik Pasha Caddesi, Istanbul. This design exercise focused on enhancing the everyday experience of the neighbourhood by injecting a new spatial program that would not disturb the existing system of the street but instead accentuated it. The intervention of the street would help the inhabitants to utilise the street as their collective living room. It would also strengthen the relationship between the inhabitants as they utilise the space together.

\subsection{Literature Review}

\section{Street as the Temporal Living Spaces}

Living in the city often includes the utilisation of the streets to support the daily necessity, although previously the street was only seen as a supporting system, or as space for circulation to connect one place to another. As the civilisation is growing toward the city due to the impact of industrial revolution and modernisation, the definition of inside and outside, as well as private and public, is challenged. The role of the street becomes more important than ever. The street transforms from transitory space into the setting where sociocultural activities occur.

The phenomenon of inhabiting the street is supported by the change in the concept of domesticity and living. Rather than focusing on the physical aspects, the contemporary definition of domesticity and living relies on something very experiential. Domesticity is produced by the feeling of familiarity which gives the senses of ownership, affection, refuge, satisfaction and contentment (Douglas, 2007 and Rybczynksi, 2011). The domestic experience and the acts of living it carries does not attach to any fixed place, rather its presence depends on its occupant's spatiotemporal situation. This shift allows the contemporaries to produce and reproduce their living space everywhere, from the realm of the houses to the realm of the streets. For the contemporaries, the street could be seen as a potential blank canvas for them to paint their living space, where they could dwell, take refuge, interact with others but still feel at home.

The idea of inhabiting the street is also incorporated in the current discourse of interior architecture design theory. The discipline of the interior is shifting from the one that concentrates on the production of objects into the discipline that focuses on the idea of "becoming" (Attiwill, 2012). It is considered as a system consisting of both tangible and intangible elements that are "signifying how things could and should be for the inhabitant" (Winton, 2013, p.48). The production of interior space is called interiorization; it is the act of "making habitable through a process of selection and arrangement to produce an intensive space; a temporal consistency, a 'fabrication of space' which enables inhabitation - spatially and subjectively" (Attiwill, 2012, p.5). Interior space that is produced by the process of interiorization is free from any positional restrictions and rather transform along with its occupants' frame of reference to benefit their physical and emotional wellbeing (Attiwill, 2012). Interiorization allows the domestication of the street and provides it with the spatial mechanisms to meet the needs of the contemporaries in the city.

The act of interiorizing the street as living spaces is a common practice in many cultures. This practice is produced by traditional activities and cultural support which usually emerge as a reaction to the current forms of urban fabric that no longer provide any spatial solution (Amoroso, 2014). The interiorization is unfolded directly from the actions of the occupants which would produce a temporal space that lies in between the domestic and public realm (Lim, 2011 and Karnchanaporn, 2014). The production of the temporal living space is the production of an urban room, a space in the city that can be engaged with and contain human experience (Farelly and Mitchell, 2011).

In urban context, the presence of this temporal living space is crucial as it serves as the threshold between the realms of the familiar and the realms of strangers. It provides the notion of comfort, one of the most complex and key aspects of the domestic interior (Winton, 2013). The collective nature of the street allows the social activities to occur in this temporary space and transform it into a collective living room where everything is co-owned and co-produced. It becomes a social space which provides at least two sets of different social relations: "that of relations between people and groups within the household or programme, and that of relations between them, and people from outside, i.e. strangers, visitors or the public" (Koch, 2013, p.067:3). The temporal living space reflects both the individual and collective identity of the city.

\subsection{Methodology}

One of the indicators that determine the quality of life is the presence of other people. They stimulate the life in the city and "heavily impact individuals' understanding of the social context of life" (Gehl and Svarre, 2013, p.17). To reveal the potential of the street in producing temporal living space, it is necessary to understand how people utilise the street to support their daily necessities (Gehl and Svarre, 2013). This understanding is important to transform the city to become more liveable and enhancing the well-being of the people. The behavioural study was conducted through the observation and recorded on the spatial mapping of activities to find the production patterns of the temporal living space. The activities observed in the neighbourhood were the primary activities in public 
space in urban context, which according to Gehl and Svarre (2013), consisted of two categories: the necessary and the optional activities.

There are two forms of mapping that would be utilised to recorded the behavioural study of people activities on the street. First is behavioural mapping which is employed to identify both stationary and transitory activities that would provide a clear description of the general pattern of the activities, the spatial components and the spatial arrangements of the street (Gehl and Svarre, 2013). According to Gehl and Svarre's (2013) behavioural mapping should be drawn in several layers of time, at different times of the day or over longer periods. The stationary activities are usually recorded from one vantage point, like plans or axonometric diagram, which would provide a picture of a moment in a given place (Gehl and Svarre, 2013). The transitory activities should be recorded by doing a detailed mapping, which could contribute to our understanding of how life in public space develops as sequences and process (Gehl and Svarre, 2013). The second form of mapping is the spatial detail mapping that would show the mechanism of spatial operation on the street in sequences and interconnectedness. These mappings would lead to the development of the design strategies to enhance the quality of life in the city.

This study takes places in the neighbourhood around Faik Pasha Caddesi in Istanbul, Turkey. Unlike any other big neighbourhood in Istanbul which street is always dominated by cars, the occupants of this neighbourhood perform the utilisation of the street as their everyday spatial practice to support their daily needs even though this is not a pedestrian-only street. The rich spatial programs and the unique relationship between each inhabitant that complemented each other in the production of this temporal living space are what intrigued this study.

\subsection{Findings}

\subsection{Behavioural Mapping of Faik Pasha Caddesi}

The neighbourhood around the Faik Pasha Caddesi has rich spatial programs, varying from residential, office to commercial activities. The occupants of this neighbourhood use a series of outdoor areas, including the streets in front of their private space, as the extension of their commercial and their domestic activities. It is quite common to see the domestic objects, along with the domestic activities, out in the street in this neighbourhood. Figure 1 illustrates how the inhabitant of Faik Pasha Caddesi utilise the street and outdoor space to support their daily necessities. This spatial practice and the activity it embodies is temporal. Its existence is highly dependent on the relationship between its occupants and its context. The presence of this temporal living space, its meaning for the local communities and its ability to attract visitors from outside of the neighbourhood to interact and share its domestic experience are the unique features of this setting.

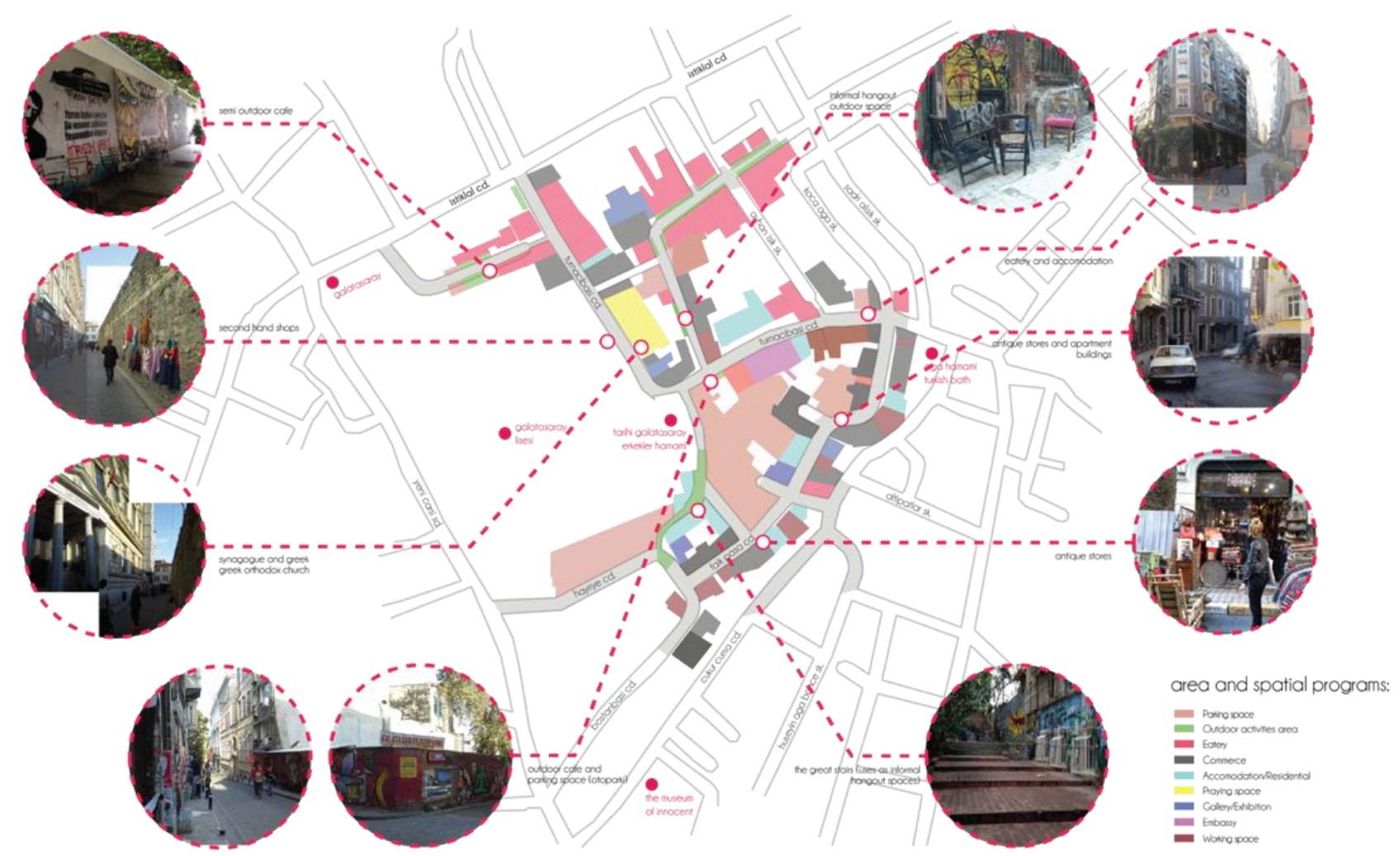

Fig 1. Faik Pasha Caddesi 
By conducting behavioural mapping, it is possible to gain an understanding of the spatial components and the mechanism of this temporal living space. This mapping would also lead to the development of the design strategies to enhance the quality of life in this neighbourhood. The mapping attempts to illustrate the primary activities that happen on the street, whether stationary or transitory, in two forms of representation. The first mapping is conducted to reveal the general pattern of activities, spatial components and arrangement that form the utilisation of the street. The second mapping shows the details of interconnection between actors and context. It explores the role of the occupants and their relationship with the spatial elements that produce the temporal living space.

The first mapping explores three spatial variables that have influences in the production of the temporal living space, such as traffic flow, spatial programming, and activities. These three variables are those that explain variety of aspects that contribute to the dynamic nature of the neighbourhood. The mapping of the traffic flow (\#1 in Fig. 2) reveals how the pedestrian, the cars, the motorcycle and the public transportation are co-existed together in this neighbourhood. The mapping shows that there are a few pedestrian-only streets, while on some other street the pedestrian and the car conflict with one another to claim their rights. The car and motorcycle traffic pace in this neighbourhood is also quite fast while there are so many domestics experiences the street could offer if it is experienced by walking.

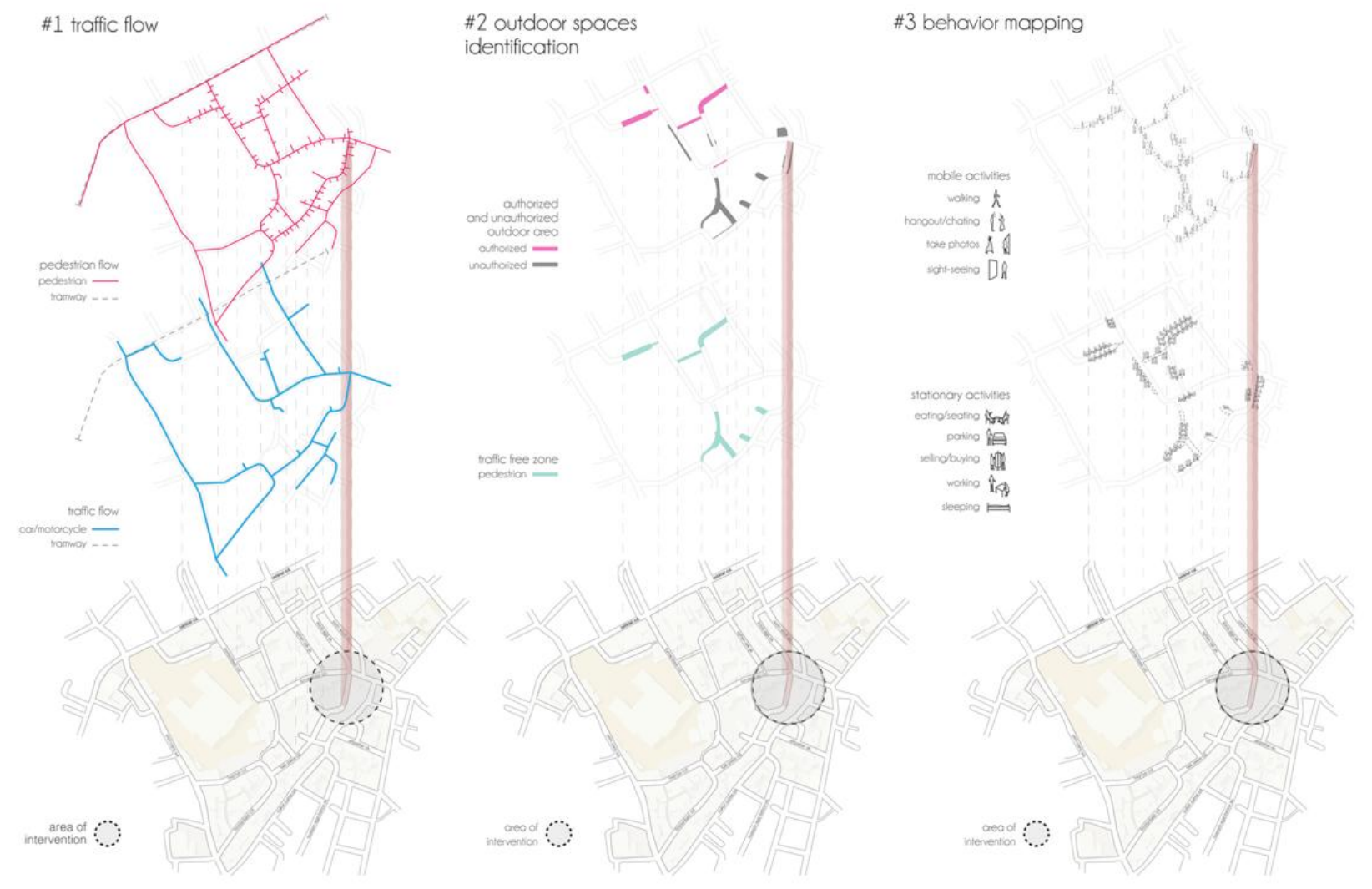

Fig 2. Mapping the Existing System of Faik Pasha Caddesi

The mapping of the spatial programming (\#2 in Fig. 2) reveals the potential site of the spatial practice conducted by the occupants to establish their temporal living space. This mapping also reveals the characteristics of the street and the alteration that has already been done by the street inhabitant to utilise the street. From this diagram, it could be seen whether the spatial operations or interiorization conducted by the inhabitants are formal or informal, authorised or unauthorised, and temporal or fixed. Meanwhile, the activities mapping (\#3 in Fig. 3) unfolds the variation of activities, whether it is stationary or transitory, its characteristics and spatial mechanism that allowed the inhabitation on the street to occurred. The stationary activities vary from sleeping, seating, eating, selling, buying, working to parking. The transitory activities are also varied, including the acts of walking, chatting, take photos and sightseeing. This mapping illustrates the rich program of the street that contributes to the production of the street as temporal living room of the city.

The second form of mapping is illustrated in Figure 3, which shows details and interconnection between the inhabitant of the existing temporal living space and the spatial elements that interiorize the street. This mapping show how each inhabitant has their spatial needs in occupy the street that requires fulfilling. For example, the buyers or visitors might need seating spaces, shelters, moderate acoustics and user-friendly signage to support their activities on the street, while children that live in this neighbourhood has different needs, such as soft surface, open space, and clean toilets. This mapping also reveals the roles of each inhabitant in support the production of the temporal living space in the street. The role of the inhabitants of Faik Pasha Caddesi are divided into two types of participation, which is shown with colours in Figure 3, the active (illustrates by the pink rectangle) and passive (white rectangle). The 
role of the inhabitants is significant as they were acting as the composer as well as the users of this temporal living space. By unfolding the spatial elements that utilise to produce the temporal living space in the street, it is possible to gather the ingredients of the spatial mechanism needed by the occupants to determine their specific role in shaping their environment and to generate spatial mechanism that would accommodate various ever-changing needs of the street's inhabitant.

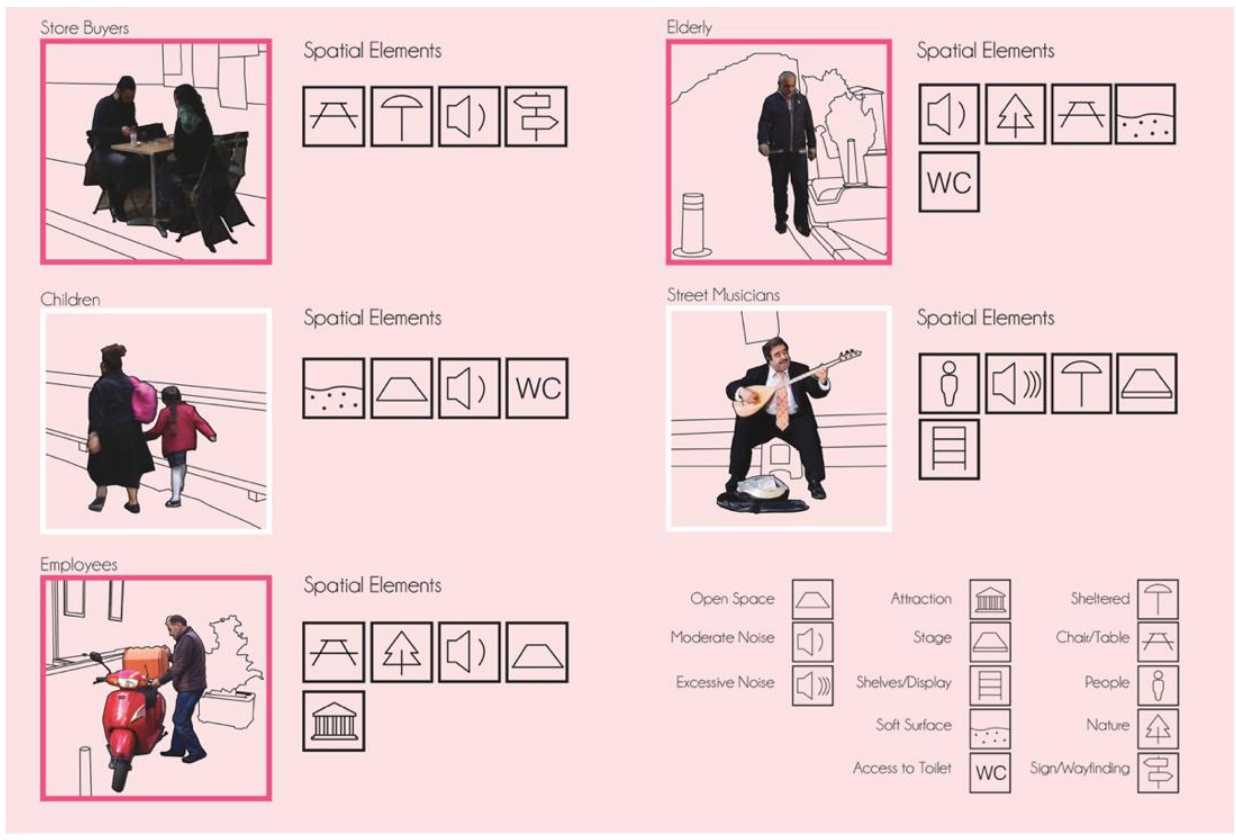

Fig 3. Mapping of the Inhabitants and Context

\subsection{Design Strategies for Faik Pasha Caddesi}

The development of the interior architectural design strategies for the Faik Pasha Caddesi is based on the spatial mechanism gathered by those previous mappings. The design strategies should generate interior intervention that both accommodate the domestic need of the occupants as well as the collective need of the neighbourhood. The design development should base on the idea of interiorization which optimised the existing potential of the context to enhance the physical and psychological well-being of the occupants (Attiwill, 2012). The existing potential highlighted in this design development is the inhabitants and their everyday objects. The design development of Faik Pasha Caddesi should not generate from a top-down approach. It should rely entirely on the participatory aspect of the inhabitants, which makes it a bottom-up approach. The architects/designers should act as facilitators, which responds the conditions of the street with the inhabitants' frame of reference, to produce an intensive space that allowed the inhabitant to be their interiorizt. This approach would generate a flexible and temporal living space that could be utilised, adjust and personalise by each of the inhabitants in Faik Pasha Caddesi.

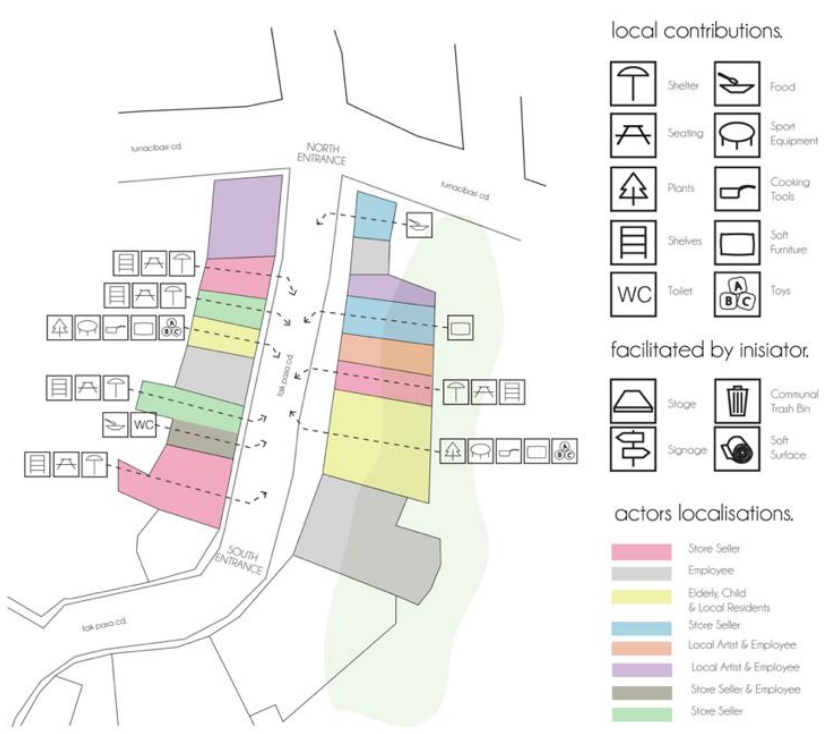

Fig 4. Identifying Potentials of Existing Context 
The first step that should be completed to be able to develop a participatory-based interior setting is unfolding and mapping all the existing potential in the context. Figure 4 shows the mapping of contribution of the Faik Pasha Caddesi's inhabitants in generating their temporary living space. This contribution list is based on the inhabitants' spatial needs mapping (Figure 3) and the possibilities to utilise their personal everyday objects to fulfil these needs. It makes the local inhabitants not only act as users but as active participants in generating their own temporal living space. The architects/designers only required to facilitate spatial elements that could be easily adjusted depending on the inhabitants' spatial-temporal conditions such as signage, soft surface material street base, and communal trash bin. This design strategy put the inhabitants with full control in generating their domestic space in the street.

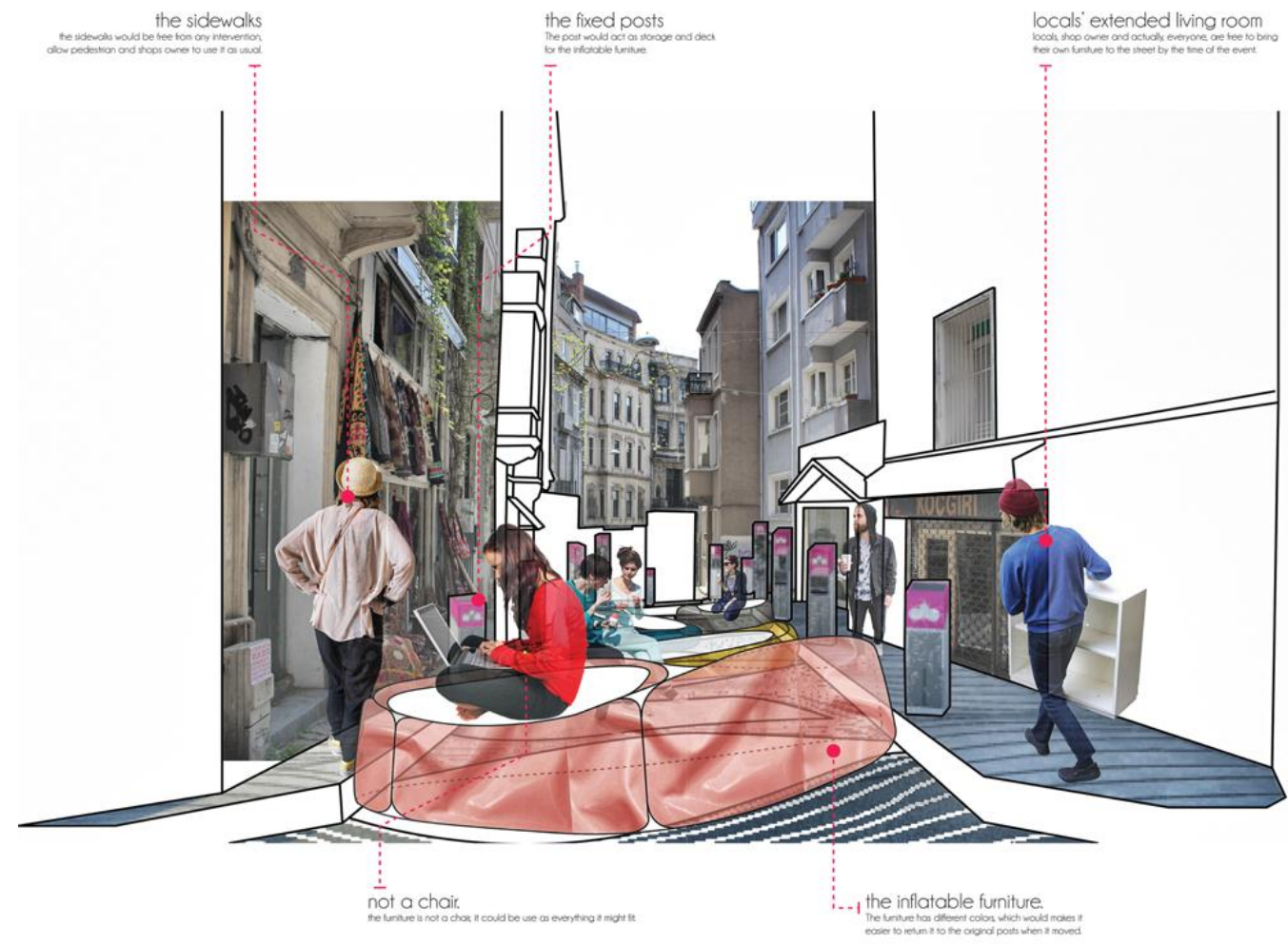

Fig 5. Design Development of the Street as Temporal Living Space

By exploiting the potential of the street, this intervention interiorizes the street by providing the basic but significant spatial elements that could be utilised alongside the inhabitant's personal everyday objects. These spatial elements are developed to provide the needs of the inhabitants as well as to make the occupants to have some control to determine their own domestic interior space in the street. The supporting design elements which were provided by the architects/designers took form as inflatable furniture that could be folded and stored away inside of a post. These posts act as a furniture storage, istanbulkart charging station, street lamp, as well as the Wi-Fi routers. These posts are designed as a fix or stationary spatial elements, whether the furniture is mobile and temporary. The fixed post along with the inflatable furniture is designed to support the practice of interiorization by the Faik Pasha Caddesi's inhabitant to domesticated the street as the extension of their living space. The existence of such urban interior practice is important to support the enhancement of wellbeing of the city's inhabitant.

\subsection{Conclusion}

This paper suggests that the idea of the street as temporal living space has an important role in enhancing the well-being of the city's inhabitant. The street, as well as any other private and public space, also has its role in accommodating the shift conception of domestic space, which is currently seen as psychological setting that is not restricted to any physical forms but depends on the feeling of ownership, of refugee, and of affection. The utilisation of the street as the living space is a common spatial practice in developing countries, yet this practice tends to be marginalised since it does not comply with the idea of ideal city. This paper aims to reveal the crucial role of the street as temporal living space by unfolding the behaviour and spatial mechanism of the inhabitants. The findings of this study, which are recorded into two forms of mapping, is then translated into design exercise that would reflect the dialogue between the street, its inhabitants and their activities. This interior architectural design exercise based on this study could be seen as the practice of interiorization, one of the design strategies that could transform the harsh urban environment into a more friendly and habitable environment. This study suggests that there is a need to develop the possibilities of different kind of temporal living space as a way to enhance the spatial experience of the city's inhabitant. 


\section{Acknowledgements}

This study was conducted as part of the IMIAD Exchange Program 2015-2016 between MFA Interior Architectural Design Program, Edinburgh College of Art, the University of Edinburgh with Interior Architecture Department, Istanbul Technical University under the supervision of Dr Bahadir Numan and Professor Edward Hollis. This project was exhibited in ECA Degree Show 2016, the University of Edinburgh.

\section{References}

Amoroso, S. (2014). Interior Urbanism in Two Asia Pacific Cities: Spatial Intensifications in Hongkong and Hanoi. Monu Magazine on Urbanism, (21 Interior Urbanism), $72-77$.

Attiwill, S. (2012) Beyond building: interior designs. IDEA Symposium 2012 (Interior: A State of Becoming), 1-7

Douglas, M. (2007) The idea of a home: a kind of place. in B. M. Lane (ed.), Housing and Dwelling: Perspectives on Modern Domestic Architecture (61-67). New York: Routledge

Farrelly, L., \& Mitchell, B. (2011). Interior Room Urban Room. In E. Hollis et al. (ed.), Interior Tools Interior Tactics: Debates in Interiors Theory and Practice. Faringdon, Oxfordshire: Libri Publishing.

Gehl, J., \& Svarre, B. (2013). How to Study Public Life. Washington: Island Press.

Karnchanaporn, N. (2014). 150cm domestiCITY. In: SITUATION Symposium. Melbourne: Interior Design, RMIT University.

Koch, D. 2013. The Architectural Interface Inside-Out: Interior-exterior relations, spatial models, and configurational mirroring. Proceedings of the Ninth International Space Syntax Symposium; 067. Seoul: Sejong University

Lim, S. (2011). Tactics of The Peripatetic: On Vendors' Making an Interior of The Street. In E. Hollis et al. (ed.), Interior Tools Interior Tactics: Debates in Interiors Theory and Practice. Faringdon, Oxfordshire: Libri Publishing.

Rybczynksi, W. (2011) Domesticity. In L. Weinthal (ed.), Toward a New Interior, An Anthology of Interior Design Theory (394-403). New York: Princeton Architectura Press

Shaw, P. and Hudson, J. (2009). The Qualities of Informal Space: (Re)appropriation within the informal, interstitial spaces of the city. In: Occupation: Negotiations with Constructed Space. Brighton: University of Brighton.

Winton, A. G. (2013). Inhabited Space: Critical Theories and the Domestic Interior. In G. Brooker \& L. Weinthal (Eds.), The Handbook of Interior Architecture and Design (20-29). London: Bloomsbury Academic Press.

Yatmo, Y. (2008). Street Vendors as 'Out of Place' Urban Elements. Journal of Urban Design, 13(3), 387-402. 